\title{
Characterization of Grape (Vitis vinifera L.) Berry Sunburn Symptoms by Reflectance
}

\author{
Laura Rustioni,* Letizia Rocchi, Eugenio Guffanti, Gabriele Cola, and Osvaldo Failla \\ CIRIVE - Centro Interdipartimentale di ricerca per l'innovazione in Viticoltura ed Enologia, Università degli Studi di Milano, via G. \\ Celoria 2, I-20133 Milano, Italy
}

\begin{abstract}
Sunburn can affect grape quality both for chemical modifications and by visual impact of the browning. Optical properties of 17 white grape accessions were investigated in the visible region using a noninvasive instrument. Reflectance spectra were obtained using a Jaz System spectrometer. Browning was induced by exposing grape bunches to direct sunlight at 12:30 p.m. for $5 \mathrm{~h}$. During the experiment, the global solar radiation ranged from 2.6 to $2.7 \mathrm{MJ} \mathrm{m}^{-2} \mathrm{~h}^{-1}$ and the air temperature from 24.3 to $29.2{ }^{\circ} \mathrm{C}$; the exposed berries reached a temperature of $34.2{ }^{\circ} \mathrm{C}$ in comparison to the $30.4{ }^{\circ} \mathrm{C}$ of the shaded ones. Differences between the spectra of controlled and exposed berries mainly emphasized the loss in chlorophyll and the formation of brown compounds. A positive correlation between the chlorophyll concentration and berry browning was proposed. Developing rapid, noninvasive, and low-cost methods based on reflectance spectroscopy could support grapevine variety characterization with respect to sunburn susceptibility as well as study of the physiological processes involved in the symptoms' appearance.
\end{abstract}

KEYWORDS: Vitis vinifera, white grapes, browning symptoms, melanin-like pigments, sun exposure

\section{INTRODUCTION}

Fruit quality involves sensory properties, nutritive value, chemical composition, structural and mechanical characteristics, and absence of defects. ${ }^{1}$ Sunburned berries exhibit a series of physiological and compositional disorders that may adversely affect market value, especially in the case of table grapes, and the final wine quality, when speaking about wine grape varieties. $^{2}$ Bunches directly exposed to sunlight may present symptoms of sunburn damages ${ }^{2}$ induced by high fluxes of solar radiation, exacerbated by high ambient temperature ${ }^{3}$ in combination with the ultraviolet radiation. ${ }^{4}$ Often this type of damage can lead to browning, cracking, or complete berry wilting and desiccation in both red- and white-berried varieties. ${ }^{2}$ The browning of the berry's exocarp is related to the loss of cell compartmentalization and to the oxidation of polyphenolic compounds by polyphenol oxidases. This results in the formation of polymerized melanin-like pigments. ${ }^{5}$ The appearance and the extent of this disorder are strongly dependent on factors such as grape variety, berry stage of development, ${ }^{2}$ and environmental conditions. ${ }^{6}$

During the past years, our research group has been particularly involved in the phenotypic evaluation of germplasm within the framework of COST Action FA1003 "Grapenet: East-West Collaboration for Grapevine Diversity Exploration and Mobilization of Adaptive Traits for Breeding". Thus, as a major objective, we have been considering the development of high-throughput methods to evaluate compositional and qualitative traits of grape cultivars. Tissue spectral signature of grapevine varieties in the visible and near-infrared ranges is mainly ruled by content, composition, and localization of pigments, epicuticular waxes, and water content. ${ }^{7-10}$ All of these factors result in defined changes in fruit absorbance and, thus, reflectance and transmittance at specific wavelengths. ${ }^{11-13}$ It follows that the typical combinations of these characters in a single species and/or cultivars can allow the assessment of their phenotypic traits on the basis of the reflected radiation. As an example, we have recently developed a method based on the reflectance spectrum for grape color phenotyping. ${ }^{14}$ The pigment (mainly chlorophylls, carotenoids, anthocyanins, and other phenolics) contents as well as their proportions determine fruit color and appearance, ${ }^{1,15}$ which represent markers for commercial quality. Nowadays, it is also possible to elucidate the contribution to the tissue color of different compounds at the molecular scale with the theoretical chemistry approach. Some examples are already available in the literature concerning differences in grape anthocyanin color $^{16}$ and copigmentation affecting the absorption properties through molecular interactions. ${ }^{17}$ Pigments undergo changes during ripening and as a result of various stresses. ${ }^{18,19}$ Thus, an understanding of fruit optical properties could support the development of sensitive techniques with the purpose of deducing the composition, structure characteristics, and response of grape tissues to specific environmental conditions and physiological disorders, such as sunburn. ${ }^{20}$ Besides the description of grape composition, phenotyping could involve the ability of the cultivars to react to specific environmental conditions.

In this paper we investigated changes in the optical properties of a number of white-berried grapes with three main objectives: (i) to identify the reflectance spectrum variations related to incipient browning symptoms appearance; (ii) to search for relationships with physiological processes involved in sunburning; (iii) to emphasize chemical composi-

Received: September 20, 2013

Revised: $\quad$ March 20, 2014

Accepted: March 20, 2014

Published: March 20, 2014 
tional markers of sunburning predisposition, with the aim of developing high-throughput methods useful in exploring the phenotypical variability of the grapes' susceptibility to sunburn damage.

\section{MATERIALS AND METHODS}

All of the Vitis vinifera L. accessions tested were grown in the same germplasm collection vineyard, located at the Regional Research Station of Riccagioia (Lombardy region, northern Italy) already described in a previous paper. ${ }^{14}$ The experimental layout provided for the selection of 17 Lombard germplasm accessions named Bianca Botticina, Bianca Gabana, Pinot bianco, Chiavennasca bianca, Colombaia bianca, Croatina bianca, Erbamat, Favorita, Invernenga, Cortese, Marzemino bianco, Pollini A, Malvasia Istriana, Verdicchio, Uva bianca dura invernale, Verdea, and Vernassa. For each accession one shaded bunch was chosen. On August 29, 2012, at 12.30 p.m. solar time, the bunches were exposed to direct sunlight by leaf removal from the southwestern side facing the sun; the epicuticular waxes were mechanically removed through a slight rubbing of the berry surface with paper towels to facilitate the sunburning symptoms' appearance and to exclude the wax heterogeneity as an additional source of variability. After 5 h, at 5.30 p.m., all of the bunches were collected.

To describe grape temperatures during the experiment, the BerryTone model ${ }^{21}$ was used to simulate the hourly temperature of the bunches. The model has been fed maximum and minimum daily air temperatures gathered by the weather station located in the vineyard.

All grape samples were kept at $10{ }^{\circ} \mathrm{C}$ and analyzed within $24 \mathrm{~h}$ from their harvesting. Forty berries were selected for each accession. Twenty of them were taken from the inner part of the shaded side of the cluster, with the purpose of describing the varietal reflectance spectra (control berries). Twenty berries on the exposed side of each bunch were also sampled (exposed berries). The most symptomatic berries (visual evidence of browning/discoloration), if present, were taken. When no symptoms were clearly visible, the most exposed berries were chosen. Before the spectrophotometric analysis, epicuticular waxes, still present in the control berries, were mechanically removed with a paper towel to avoid their interference with the optical properties. ${ }^{10}$ Overall, 680 reflectance spectra were obtained using a Jaz System spectrometer (Ocean Optics), completed with a channel with a DPU module and an ILX511b detector, an OFLV-3 filter, an L2 lens, and a $50 \mu \mathrm{m}$ slit as installed options. A reflection probe QR600-7VIS125 consisting of a tight bundle of seven optical fibers $(600 \mu \mathrm{m}$ in diameter), in a stainless steel ferrule (six illumination fibers around one read fiber), was coupled to the spectrophotometer. The instrument was set up with a NIR-vis light source (Ocean Optics) 4095 power setting and an integration time automatically corrected by the instrument. Collected spectra ranged between 341 and $1025 \mathrm{~nm}$ and had a spectral resolution of about $0.3 \mathrm{~nm}$. In this work, the visible spectral changes $(450-750 \mathrm{~nm})$ will be presented and discussed. Each spectrum was set up to be the average of nine spectra, which were directly calculated by the instrument. The spectra were converted in percentage of reflectance $(\% R)$ after a calibration with a blank, obtained by using a white Spectralon surface (Labsphere). The relationship between reflectance signal and chromophore content is nonlinear. Thus, the reflectance spectra were converted to approximate to the (quasi)linear relationship between pigment content and optical reflectance-based indices using reciprocal reflectance $(1 / R)$ spectra. The difference between exposed and shaded spectra was than calculated (Figure 3a). To make the browning contribution more apparent, a normalization to chlorophyll red maximum $(678 \mathrm{~nm})$ was also performed before the differential spectra were calculated, obtaining the " $1 / R$ (chlorophyll normalized)" spectra (Figure $3 b$ ).

Chlorophyll content was estimated by using a reflectance index previously developed by Merzlyak and Solovchenko: ${ }^{22}$

$$
\text { chlorophyll index }=R_{800} / R_{678}
$$

This index was developed in apple fruits, but we decided to apply it to grapes because (i) the optical effect of chlorophylls in the red region is clearly identified in white grape spectra and (ii) no interferences from other white grape pigments are expected at these wavelengths. ${ }^{14}$

The index was computed on the basis of the average control spectrum of each cultivar. The objective was to evaluate the berry susceptibility to sunburn in relation to the initial chlorophyll content.

A browning intensity index was developed to evaluate the degree of sunburning symptoms in each accession. It was calculated as the difference of the inverse reflectance spectra, normalized to chlorophyll " $1 / R$ (chlorophyll normalized)" at the maximum absorption wavelength $(490 \mathrm{~nm})$ of melanin-like pigments.

$$
\text { browning intensity index }=\frac{100 R_{\mathrm{e} 678}}{R_{\mathrm{e} 490}}-\frac{100 R_{\mathrm{s} 678}}{R_{\mathrm{s} 490}}
$$

where $R_{\mathrm{e} 678}=$ exposed berries' reflectance at $678 \mathrm{~nm}, R_{\mathrm{e} 490}=$ exposed berries' reflectance at $490 \mathrm{~nm}, R_{\mathrm{s} 678}=$ shaded berries' reflectance at 678 $\mathrm{nm}$, and $R_{\mathrm{s} 490}=$ shaded berries' reflectance at $490 \mathrm{~nm}$.

The statistical significance of the differences between reflectance data from exposed and control skins was estimated for each wavelength according to the classical computation of the mean confidence intervals per $p=0.95$, with the lower limit $=M-$ $\left(t_{0.95}\right)\left(s_{\mathrm{m}}\right)$ and the upper limit $=M+\left(t_{0.95}\right)\left(s_{\mathrm{m}}\right)$, where $M=$ average value, $t=$ Student's $t$ per $p=0.95$, and $s_{\mathrm{m}}=$ standard error (standard deviation/number of berries ${ }^{1 / 2}$ ). This analysis, as well as correlations and ANOVA models, was performed by SPSS statistical software (version PASW Statistics 19, SPSS Inc., Chicago, IL, USA).

\section{RESULTS}

During the experiment, the global solar radiation ranged from 2.6 to $2.7 \mathrm{MJ} \mathrm{m}^{-2} \mathrm{~h}^{-1}$ and the air temperature from 24.3 to 29.2 ${ }^{\circ} \mathrm{C}$. The hourly course of berry temperature for the day of the experiment was simulated with reference to a southwestern exposed part of the bunch in comparison to the shaded side (Figure 1). The exposed berries reached a maximum temper-

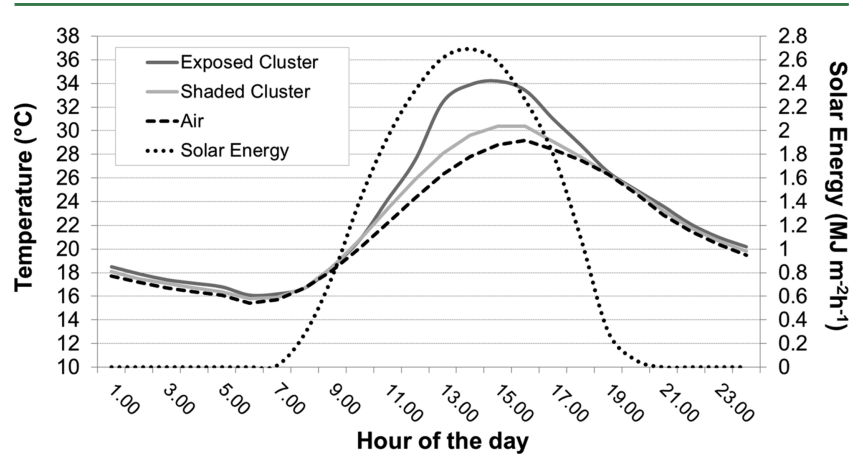

Figure 1. Daily course of solar energy and temperatures (air, sunexposed and shaded berries). Bunches were exposed on August 29, 2012, at 12.30 p.m. solar time for $5 \mathrm{~h}$.

ature of $34.2{ }^{\circ} \mathrm{C}$ at 2:00 p.m. At the same time the control berries were at $30.4{ }^{\circ} \mathrm{C}$ and the air at $29.2{ }^{\circ} \mathrm{C}$. The difference between air and berry temperature was maximum at 1:00 and 2:00 p.m., when $6.1^{\circ} \mathrm{C}$ was reached. At that time the difference between exposed and shaded berries was $4.3{ }^{\circ} \mathrm{C}$.

Reflectance spectra were measured and their relative standard error was calculated for control and exposed berries to describe sunburning effects (Figure 2). Reflectance spectra minima indicate the presence of compounds absorbing in the corresponding spectral band. Figure 3 represents the variation of reciprocal reflectance $(1 / R)$ (Figure $3 a$ ) and $1 / R$ (chlorophyll normalized) (Figure $3 \mathrm{~b}$ ) spectra in relation to sunburning. In Figure 3, when the interval of confidence overlaps zero, no significant compositional changes occurred in relation to sunlight exposure of berries. If it is above zero, new 


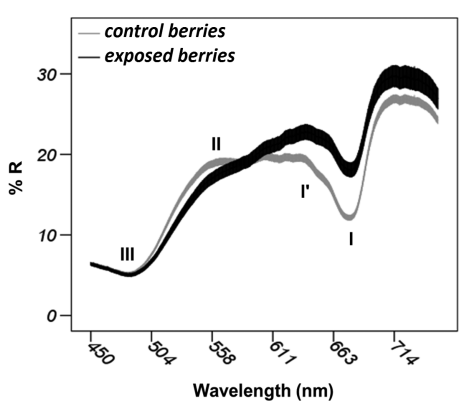

Figure 2. Control and exposed berry average spectra ( \pm standard errors). Roman numbers indicate spectral regions of specific absorption interest.

molecules absorbing in the corresponding wavelength range have been generated (e.g., melanin-like pigments). Differences lower than zero are indicative of chromophore loss as a consequence of sunburn-induced bleaching.

It is possible to note three spectral regions (Figure 2) related to different grape skin compounds. Molecules related to region I (chlorophylls, Figure 2) evidently undergo degradation during sunburn (Figure 3a). In Figure 2, region II mainly indicates a difference between control and exposed spectra, related to the formation of brown compounds. In Figure 3 the absorption signature of melanin-like pigments clearly appears. The maximum of reciprocal reflectance $(1 / R)$ spectra (Figure $3 \mathrm{a}$ ) underwent an $18 \mathrm{~nm}$ shift toward shorter wavelength after normalization to the chlorophyll red absorption maximum (Figure 3b). Region III (Figure 2) indicates a strong overlapping absorption by several chromophores (e.g., chlorophylls, carotenoids, melanin-like pigments).

\section{DISCUSSION}

In the red region, a broad band of combined chlorophyll $a$ and $b$ absorption was detected in the control and exposed berry spectra (Figure 2, region I). In Figure 2 the minimum of reflectance near $678 \mathrm{~nm}$ should be mostly due to chlorophyll $a$ (spectral region I), whereas the little shoulder near $650 \mathrm{~nm}$ should be related to chlorophyll $b$ absorption (spectral region $\left.\mathrm{I}^{\prime}\right)$, as suggested by Merzlyak et al. ${ }^{23}$

In comparison with the control spectrum, the exposed one (Figure 2) showed a decrease in reflectance in region II. This trend, emerging during browning, may be explained by the generation of melanin-like pigments, ${ }^{5,24}$ for example, via the oxidation of polyphenols by polyphenol oxidases. ${ }^{25}$

In the blue and green region (Figure 2, region III), no significant difference was recorded. In this region, different molecules absorb, including chlorophylls. Chlorophylls underwent degradation (Figure 3a). Nevertheless, the expected increase in reflectance in the Soret band (see band III in Figure 2) was not detected, probably due to accumulation of other chromophores, most probably the browning pigments. ${ }^{20}$ The normalization of reciprocal reflectance spectra to chlorophyll allows the exclusion of the overlap in region III between the absorption of chlorophylls and melanin-like pigments. Thus, the hypsochromic shift of the melanin-like pigments $\lambda_{\max }$ between panels $a$ and $b$ of Figure 3 should be related to the removal of this overlapping contribution by chlorophylls to overall.

Figure 4 shows the correlation between the varietal (shaded bunches) chlorophyll concentrations and the browning

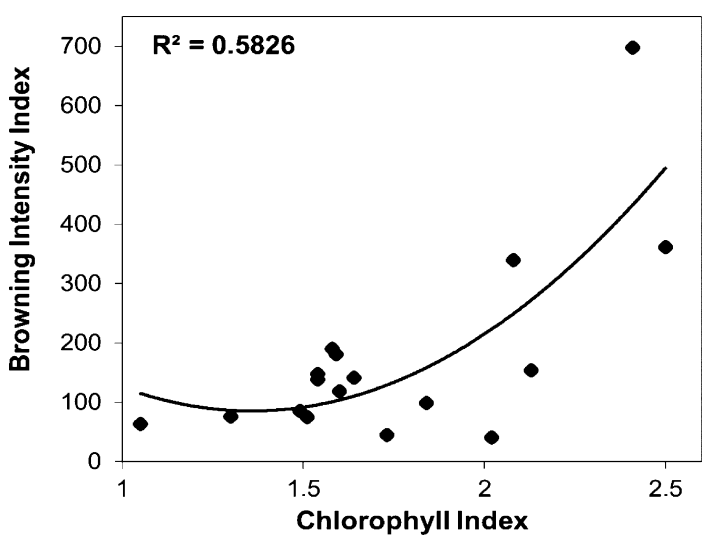

Figure 4. Nonlinear correlation between chlorophyll index and browning intensity index $(p<0.01)$.

intensity index and, thus, melanin-like pigment generation. A quadratic model was able to describe the nonlinear relationship. As expected in oxidative processes, the reaction kinetics appears above a threshold. After a chlorophyll index value of about 2, the production of melanin-like compounds suddenly increased. Below the threshold, no relationships could be detected. Thus, it is possible to suggest a central role of photo-oxidation in the sunburn symptom physiology. For this reason it is possible to
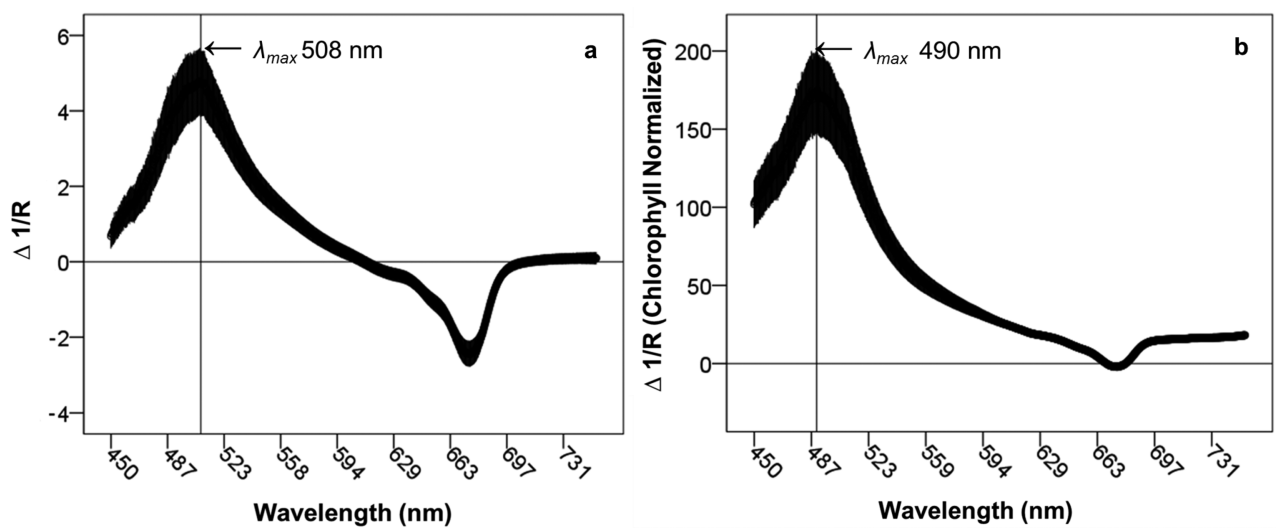

Figure 3. Differences (mean \pm confidence interval 95\%) in the (a) reciprocal reflectance $(1 / R)$ and (b) $1 / R$ (chlorophyll normalized) spectra between exposed and shaded berries. 
propose the use of a chlorophyll index threshold as a marker for grapes' susceptibility to sunburning browning. Further experiments could confirm this hypothesis, studying the kinetics of browning of individual berries and relating the parameters of these kinetics to the initial chlorophyll content.

With the development of rapid, noninvasive, and low-cost methods, reflectance spectroscopy could support grapevine variety characterization with respect to sunburn susceptibility, as well as the study of the physiological processes involved in the symptoms' appearance.

\section{AUTHOR INFORMATION}

\section{Corresponding Author}

*(L.R.) E-mail: laura.rustioni@unimi.it. Phone: 003902503 16556. Fax: 00390250316553.

\section{Funding}

The research leading to these results has received funding from the European Community's Seventh Framework Programme (FP7/2007-2013) under Grant Agreement FP7-311775, Project Innovine. Publication of the COST Action FA1003 "East-West Collaboration for Grapevine Diversity Exploration and Mobilization of Adaptive Traits for Breeding".

\section{Notes}

The authors declare no competing financial interest.

\section{ACKNOWLEDGMENTS}

We thank Dr. Marina Fogarty for revision of the English text.

\section{REFERENCES}

(1) Abbott, J. A. Quality measurement of fruit and vegetables. Postharvest Biol. Technol. 1999, 15, 207-225.

(2) Krasnow, M. N.; Matthews, M. A.; Smith, R. J.; Benz, J.; Weber, E.; Shackel, K. A. Distinctive symptoms differentiate four common types of berry shrivel disorder in grape. Calif. Agric. 2010, 64, 3.

(3) Jones, A. L.; Aldwinckle, H. S. Compendium of Apple and Pear Diseases; American Phytopathological Society: St. Paul, MN, USA, 1990.

(4) Schrader, L. E.; Zhang, J.; Sunday, J.. Environmental stresses that cause sunburn of apple. Acta Hortic. 2003, 618, 397-405.

(5) Vaughn, K. C.; Duke, S. O. Function of polyphenol oxidase in higher plants. Physiol. Plant. 1994, 60, 106-112.

(6) Bramlage, W. J.; Weis, S. A. Effect of temperature, light, and rain fall on superficial scald susceptibility in apples. J. Am. Soc. Hortic. Sci. 1997, 32, 808-811.

(7) Butler, W. L.; Norris, K. H. The spectrophotometry of dense light-scattering material. Arch. Biochem. Biophys. 1960, 87, 31-40.

(8) Gitelson, A. A.; Gritz, U.; Merzlyak, M. N. Relationships between leaf chlorophyll content and spectral reflectance and algorithms for non-destructive chlorophyll assessment in higher plant leaves. J. Plant Physiol. 2003, 160, 271-282.

(9) Solovchenko, A.; Merzlyak, M. Optical properties and contribution of cuticle to UV protection in plants: experiments with apple fruit. Photochem. Photobiol. Sci. 2003, 2, 861-866.

(10) Rustioni, L.; Maghradze, D.; Failla, O. Optical properties of berry epicuticular waxes in four Georgian grape cultivars (Vitis vinifera L.). S. Afr. J. Enol. Vitic. 2012, 33 (2), 138-143.

(11) McClure, W. F. A spectrophotometric technique for studying the browning reaction in tobacco. Trans. ASAE 1975, 18, 380-383.

(12) Merzlyak, M. N.; Gitelson, A. A.; Chivkunova, O. B.; Rakitin, V. Y. Non-destructive optical detection of leaf senescence and fruit ripening. Physiol. Plant. 1999, 106, 135-141.

(13) Solovchenko, A. E.; Merzlyak, M. N.; Pogosyan, S. I. Nondestructive estimation pigment content, ripening, quality and damage in apple fruit with spectral reflectance in the visible range. Fresh Produce 2010, 4 (1), 91-102.
(14) Rustioni, L.; Basilico, R.; Fiori, S.; Leoni, A.; Maghradze, D.; Failla, O. Grape colour phenotyping: development of a method based on the reflectance spectrum. Phytochem. Anal. 2013, 24, 453-459.

(15) Saure, M. C. External control of anthocyanin formation in apple. Sci. Hortic. 1990, 42, 181-218.

(16) Rustioni, L.; Di Meo, F.; Guillaume, M.; Failla, O.; Trouillas, P. Tuning color variation in grape anthocyanins at the molecular scale. Food Chem. 2013, 141, 4349-4357.

(17) Di Meo, F.; Sancho Garcia, J. C.; Dangles, O.; Trouillas, P. Highlights on anthocyanin pigmentation and copigmentation: a matter of flavonoid П-stacking complexation to be described by DFT-D. J. Chem. Theory Comput. 2012, 8, 2034-2043.

(18) Knee, M. Anthocyanin, carotenoid, and chlorophyll changes in peel of Cox's Orange Pippin apples during ripening on and off the tree. J. Exp. Bot. 1972, 23, 184-196.

(19) Merzlyak, M. N.; Chivkunova, O. B. Light induced pigment changes and evidence for anthocyanin photoprotection in apples. J. Photochem. Photobiol. (B) 2000, 55, 155-163.

(20) Chivkunova, O. B.; Solovchenko, A. E.; Sokolova, S. G.; Merzlyak, M. N.; Reshetnikova, I. V.; Gitelson, A. A. Reflectance spectral features and detection of superficial scald-induced browning in storing apple fruit. J. Russ. Phytopathol. Soc. 2001, 2, 73-77.

(21) Cola, G.; Failla, O.; Mariani, L. BerryTone - a simulation model for the daily course of grape berry temperature. Agric. For. Meteorol. 2009, 149 (8), 1215-1228.

(22) Merzlyak, M. N.; Solovchenko, A. E. Photostability of pigments in ripening apple fruit: a possible photoprotective role of carotenoids during plant senescence. Plant Sci. 2002, 163 (4), 881-888.

(23) Merzlyak, M. N.; Solovchenko, A. E.; Gitelson, A. A. Reflectance spectral features and non-destructive estimation of chlorophyll, carotenoid and anthocyanin content in apple fruit. Postharvest Biol. Technol. 2003, 27, 88-103.

(24) Butt, V. S. Oxygenation and oxidation in the metabolism of aromatic compounds. Proc. Phytochem. Soc. Eur. 1985, 25, 349-365.

(25) Lurie, S.; Pesis, E.; Ben-Arie, R. Darkening of sunscald on apples in storage is a non-enzymatic and non-oxidative process. Postharvest Biol. Technol. 1991, 1, 119-125. 